Recepción: 15 / 04 / 2017

Ciencias Jurídicas

Aceptación: 01 / 05 / 2017

Revisión de Literatura

Publicación: 15 / 05 / 2017

\title{
Riesgos laborales en las empresas
}

\section{Occupational hazards in companies}

\section{Riscos profissionais nas empresas}

Janet P. Pantoja-Rodríguez janet.pantojaro@ug.edu.ec

\author{
Sidia E. Vera-Gutiérrez" \\ sidiavera@yahoo.com
}

Teresa Y. Avilés-Flor "' avilesft@ug.edu.ec

Correspondencia: janet.pantojaro@ug.edu.ec

Master en Dirección Comercial y Marketing; Diploma Superior en Docencia Universitaria; Ingeniero Comercial; Profesora Especialización Educación Primaria; Universidad de Guayaquil, Ecuador.

II. Magister Ejecutivo en Dirección de Empresas con Énfasis en Gerencia Estratégica; Diplomado Superior en Gerencia de Marketing; Especialista en Gerencia de Proyectos; Ingeniera Comercial; Contadora Publica Autorizada; Universidad Agraria del Ecuador, Ecuador.

III. Magister Ejecutiva en Dirección de Empresas con Énfasis en Gerencia Estratégica; Especialista en Gerencia de Proyectos; Diplomado Superior en Gerencia de Marketing; Ingeniera Comercial; Contadora Publica Autorizada; Universidad de Guayaquil, Ecuador. 


\section{Resumen}

Los riesgos laborales son aquellos peligros existentes en el entorno o lugar de trabajo, los que puede provocar cualquier incidente o tipo de siniestro que puede ocasionar heridas, daños físicos o psicológicos, traumatismos, entre otros. El objetivo principal es de eliminar o reducir la probabilidad del accidente o enfermedad al que está expuesto cada persona en sus tareas diarias; es decir, planificar y tomar medidas preventivas que evitarán que se produzca un accidente laboral. Las herramientas de la prevención de riesgo laboral se basa en la evaluación de riesgos que estudian las condiciones del puesto de trabajo, maquinarias, productos, entre otros, adicionalmente se verifica el tiempo expuesto a cada uno de los peligros y la gravedad de los daños, posteriormente se obtiene el mayor o menor riesgo posible y finalmente se obtienen las medidas preventivas para eliminar o reducir los peligros en el cargo de trabajo. Las técnicas o disciplinas preventivas son para la seguridad en el trabajo, la higiene industrial o higiene laboral, la ergonomía, psicología laboral y medicina del trabajo. Para la prevención de los riesgos laborales se debe evaluar los posibles riesgos en los diferentes puestos de trabajo y luego debe eliminar los riesgos que sean evitables y minimizar los no evitables para tener un ambiente adecuado y seguro en la empresa.

Palabras clave: Riesgos laborales; trabajo; prevención; ambiente adecuado; empresa. 


\begin{abstract}
Occupational hazards are those hazards in the environment or workplace, which can cause any type of incident or accident that can cause injury, physical or psychological harm, trauma, among others. The main objective is to eliminate or reduce the likelihood of an accident or illness that is exposed every person in their daily tasks; ie, plan and take preventive measures that will prevent an accident occurs. The tools of prevention of occupational risks is based on risk assessment studying the conditions of the workplace, machinery, products, among others, additional time exposed is verified each of the hazards and severity of the damage, then the higher or lower potential risk is obtained and finally preventive measures to eliminate or reduce hazards in office work measures are obtained. Preventive techniques or disciplines are for occupational safety, industrial hygiene and occupational hygiene, ergonomics, occupational psychology and medicine. For prevention of occupational risks should assess potential risks in different jobs and then to eliminate the risks that are avoidable and minimize unavoidable to have a suitable and safe environment in the company.
\end{abstract}

Key words: Occupational hazards; work; prevention; appropriate environment; company. 


\section{Resumo}

Os perigos ocupacionais são aqueles perigos no ambiente ou local de trabalho, que podem causar qualquer tipo de incidente ou acidente que pode causar ferimentos, dano físico ou psicológico, trauma, entre outros. O objetivo principal é eliminar ou reduzir a probabilidade de um acidente ou doença que é exposta cada pessoa em suas tarefas diárias; Ou seja, planejar e tomar medidas preventivas que evitem um acidente ocorre. As ferramentas de prevenção de riscos ocupacionais baseiam-se na avaliação de risco estudando as condições do local de trabalho, máquinas, produtos, entre outros, tempo adicional exposto é verificado cada um dos perigos e gravidade do dano, então o maior ou menor risco potencial é obtido $\mathrm{E}$, finalmente, medidas preventivas para eliminar ou reduzir os riscos nas medidas de trabalho de escritório são obtidas. As técnicas ou disciplinas preventivas são para a segurança ocupacional, higiene industrial e higiene ocupacional, ergonomia, psicologia ocupacional e medicina. Para prevenção de riscos ocupacionais deve avaliar riscos potenciais em diferentes trabalhos e, em seguida, eliminar os riscos que são evitáveis e minimizar inevitável para ter um ambiente adequado e seguro na empresa.

Palavras chave: Riscos ocupacionais; trabalhos; prevenção; ambiente adequado; empresa. 


\section{Introducción.}

\section{Empresas}

La empresa es una entidad conformada básicamente por personas, aspiraciones, realizaciones, bienes materiales y capacidades técnicas y financieras; todo lo cual, le permite dedicarse a la producción y transformación de productos y/o la prestación de servicios para satisfacer necesidades y deseos existentes en la sociedad, con la finalidad de obtener una utilidad o beneficio Estructura básica de lo que es una empresa:

Entidad: Es decir, que una empresa es una colectividad considerada como unidad (por ejemplo, una corporación, compañía, institución, etc., tomada como persona jurídica) o un ente individual conformado por una sola persona (por lo general, el propietario).

Elementos humanos: Se refiere a que toda empresa está conformada por personas que trabajan y/o realizan inversiones para el desarrollo.

Aspiraciones: Son las pretensiones o deseos por lograr algo que tienen las personas que conforman la empresa.

Realizaciones: Se entiende como las satisfacciones que sienten los miembros de la empresa cuando logran cumplir aquello que aspiraban.

Bienes materiales: Son todas las cosas materiales que posee la empresa, como; instalaciones, oficinas, mobiliario, etc.

Capacidad técnica: Es el conjunto de conocimientos y habilidades que poseen los miembros de la empresa para realizar o ejecutar algo. 
Capacidad financiera: Se refiere a las posibilidades que tiene la empresa para realizar pagos e inversiones a corto, mediano y largo plazo para el desarrollo y crecimiento, además de tener liquidez y margen de utilidad de operaciones (por citar algunas).

Producción, transformación y/o prestación de servicios: Se refiere a que la empresa puede realizar una o más de las siguientes actividades:

Fabricar, elaborar o crear cosas o servicios con valor económico, transformar o cambiar, por ejemplo, una materia prima en un producto terminado y prestar servicios.

\section{Satisfacción de necesidades y deseos}

\section{Administración}

El concepto de administración hace referencia al funcionamiento, la estructura y el rendimiento de las organizaciones. El término proviene del latín ad-ministrare ("servir") o ad manus trahere ("manejar" o "gestionar").

La noción también puede utilizarse para nombrar a una autoridad pública, como el gobierno de un territorio, o a los responsables de una entidad privada, como los directivos de una empresa.

La administración puede ser entendida como la disciplina que se encarga de realizar una gestión de los recursos (ya sean materiales o humanos) en base a criterios científicos y orientada a satisfacer un objetivo concreto.

Por otra parte, la administración pública de un Estado es el conjunto de los organismos que se encargan de aplicar las directivas indispensables para el cumplimiento de las leyes y las normas. 
Los edificios públicos y los funcionarios también componen a la administración pública, que aparece como el nexo entre el poder político y la ciudadanía.

Hay veces en que el término administración se utiliza para denominar a la ciencia social conocida como administración de empresas. Esta ciencia estudia la organización de las compañías y la forma en que gestionan los recursos, los procesos y los resultados de las actividades.

En el estudio administrativo se intenta analizar a las empresas y las organizaciones e intentar comprender el real funcionamiento, la evolución, crecimiento y conducta. Si la técnica no se basara en el conocimiento de la ciencia, entonces se estará frente a un ensayo empírico, donde se está actuando de una forma que no puede ser considerada científica.

\section{Riesgos}

El riesgo es la probabilidad de que una amenaza se convierta en un desastre. La vulnerabilidad o las amenazas, por separado, no representan un peligro. Pero si se juntan, se convierten en un riesgo, o sea, en la probabilidad de que ocurra un desastre.

Sin embargo, los riesgos pueden reducirse o manejarse. Si somos cuidadosos en nuestra relación con el ambiente, y es posible de estar conscientes de las debilidades y vulnerabilidades que se poseen frente a las amenazas existentes, se puede tomar medidas para asegurarse de que las amenazas no se conviertan en desastres.

\section{Factor de riesgo}

Elemento que, estando inevitablemente presente en las condiciones de trabajo, puede desencadenar un menoscabo en el nivel de salud del trabajador. 
Los factores de riesgo tienen una relación o dependencia directa de las condiciones de seguridad. Éstas siempre tendrán origen en alguno de los cuatro aspectos del trabajo siguientes:

Local de trabajo (instalaciones eléctricas, de gases, prevención de incendios, ventilación, temperaturas, etc.).

Organización del trabajo (carga física y/o mental, organización y ordenación del trabajo, monotonía, repetitividad, ausencia de creatividad, aislamiento, participación, turnicidad, etc.).

Tipo de actividad (equipos de trabajo: ordenadores, máquinas, herramientas..., almacenamiento y manipulación de cargas, etc.).

Materia prima (materiales inflamables, productos químicos peligrosos, etcétera).

\section{Labores}

La palabra labor se originó en idéntico término latino, resultado del verbo "laborare" el que fue tomado del indoeuropeo "leb" con el significado de "colgar". Para otros autores la procedencia sería del griego "labeo" que haría referencia a soportar un peso. En el latín vulgar se usó la palabra trabajo.

En la actualidad la labor y el trabajo son términos sinónimos. Así es igual decir jornada de trabajo que jornada laboral, trabajo o labor manual, etcétera.

Sin embargo, paulatinamente la mujer comenzó a ocupar laboralmente puestos antes reservados a los hombres no solo por serle imprescindible para la subsistencia sino por gusto o vocación; lo que hace que en los tiempos también las labores domésticas sean compartidas en el seno familiar por hombres y mujeres, en estrecha colaboración. 


\section{Las labores humanas pueden ser o no remuneradas}

Entre las primeras se cita las domésticas (hacer la comida, limpiar la casa, lavar la ropa, etcétera) las de capacitación (por ejemplo: "Estudiar es una labor que te traerá recompensas futuras") o las comunitarias (como por ejemplo ejercer un voluntariado en un asilo de ancianos o en un orfanato o la labor de los misioneros). Las remuneradas pueden encuadrar en autónomas o por cuenta propia o las que se hacen bajo relación de dependencia.

\section{Empleados}

Generalmente se designa con este nombre al funcionario técnico o profesional que presta la actividad al gobierno para la realización de fines de interés público. Este concepto era casi exclusivo hasta concluir el siglo xix. En la actualidad, se distingue entre el empleado del Derecho Administrativo, el que acaba de definirse, y el del Derecho Laboral, donde tiende a oponerse a obrero, dentro del común denominador del vocablo trabajador. Para acentuar las diferencias, en la Administración se utiliza la denominación de empleado público; y en el mundo general del trabajo industrial, agrícola, mercantil, etc., se habla de empleado particular o privado. Este último es el que desempeña un cargo técnico y burocrático al servicio de un establecimiento o persona particular.

La distinción entre empleados y obreros es aceptada en el lenguaje corriente e incluso en las legislaciones. Se tiene en cuenta la jerarquía social, ya que el empleado suele catalogarse entre la denominada clase media; y el obrero entre las populares; la remuneración de aquél recibe casi siempre el nombre de sueldo; y la de éste, con mayor frecuencia, la de jornal o salario: en aquél predominan las tareas intelectuales o de oficina, las de trámite, registro, archivo, etc.; en los obreros se advierte el mayor esfuerzo muscular o físico, la realización de labores manuales, de limpieza y de mera vigilancia, entre otras. 
En verdad, en la producción existen zonas intermedias donde intervienen elementos, como los técnicos, capataces, etc., donde resulta difícil precisar si predomina la labor muscular o la intelectual, distinción ésta la más indicada para diferenciar a unos y otros trabajadores.

\section{Empresa}

Una empresa es una organización con fines de lucro que otorga un servicio o bien a la sociedad. Desde el punto de vista de la economía, una empresa es la encargada de satisfacer las demandas del mercado. Para lograr los objetivos esta coordina el capital y el trabajo y hace uso de materiales pasivos tales como tecnología, materias primas, etc.

Según la actividad, las empresas se clasifican en empresas de servicios, comerciales, extractivas o industriales; según la dimensión, en microempresa, pequeña empresa, mediana empresa o gran empresa; según la forma jurídica, en empresas individuales, societarias o cooperativas; según la titularidad del capital, en empresas públicas, estatales o mixtas; y finalmente, según el lugar donde actúan, las empresas se clasifican en empresas locales, regionales, nacionales o multinacionales.

El origen de las empresas tal como se las concibe hoy en día debe rastrearse en momentos claves del desarrollo del capitalismo, especialmente en el siglo XIX, con la revolución industrial y la difusión de las ideas de Adam Smith. Esta época coincide con los primeros trabajos relativos a cómo administrar y organizar una empresa de modo más sistemático.

La empresa tiene un rol sumamente importante en el desarrollo de la sociedad en general. Además de generar empleo, suministra aquellos bienes y servicios satisfaciendo necesidades en general, otorga créditos motivando la inversión y la posibilidad de compra y hace conocer 
continuamente productos útiles a través de la publicidad. No obstante, todas estas posibilidades solo tienen lugar en una economía de mercado.

\section{Evaluar los riesgos}

La evaluación de los riesgos laborales es el proceso dirigido a estimar la magnitud de los riesgos que no hayan podido evitarse, obteniendo la información necesaria para que el empresario esté en condiciones de tomar una decisión apropiada sobre la necesidad de adoptar medidas preventivas y, en tal caso, sobre el tipo de medidas que deben adoptarse.

¿Qué se debe evaluar?

Se deben evaluar los riesgos presentes en cada puesto de trabajo. Para ello, se tendrán en cuenta, por un lado, las condiciones de trabajo existentes y, por otro, el trabajador que ocupa el puesto. En particular, la evaluación de riesgos tomará en consideración, entre otros, los siguientes aspectos:

Las características de los locales.

Las instalaciones.

Los equipos de trabajo existentes.

Los agentes químicos, físicos y biológicos presentes o empleados en el trabajo.

La propia organización y ordenación del trabajo en la medida en que influyan en la magnitud de los riesgos. 
Así mismo, deberá tenerse en cuenta la posibilidad de que el trabajador que ocupe ese puesto de trabajo sea especialmente sensible, por las características personales o estado biológico conocido, a alguna de dichas condiciones.

En particular, se tendrán en cuenta los agentes, procedimientos y condiciones de trabajo que pueden influir negativamente en la salud de las trabajadoras embarazadas o en período de lactancia natural, del feto o del niño durante el período de lactancia natural, en cualquier actividad susceptible de presentar un riesgo específico de exposición.

En todo caso la trabajadora embarazada no podrá realizar actividades que supongan riesgo de exposición a los agentes o condiciones de trabajo incluidos en la lista no exhaustiva de la parte A del anexo VIII, cuando, de acuerdo con las conclusiones obtenidas de la evaluación de riesgos, ello pueda poner en peligro la seguridad o la salud o la del feto. Igualmente, la trabajadora en período de lactancia no podrá realizar actividades que supongan el riesgo de una exposición a los agentes o condiciones de trabajo enumerados en la lista no exhaustiva del anexo VIII, parte B, cuando de la evaluación se desprenda que ello pueda poner en peligro la seguridad o la salud o la del niño durante el período de lactancia natural. En los casos previstos en este párrafo, se adoptarán las medidas previstas en el artículo 26 de la Ley 31/1995, de 8 de noviembre, de Prevención de Riesgos Laborales, con el fin de evitar la exposición a los riesgos indicados.

La evaluación debe servir para identificar los elementos peligrosos, los trabajadores expuestos y la magnitud de los riesgos. Al final del proceso, deberá documentarse la evaluación de los riesgos, incluido el resultado de los controles periódicos de las condiciones de trabajo y de la actividad de los trabajadores. 


\section{¿Cuándo se debe efectuar la evaluación de los riesgos?}

La evaluación de los riesgos que no hayan podido evitarse deberá extenderse a cada uno de los puestos de trabajo de la empresa en que concurran dichos riesgos y deberá realizarse o revisarse:

\section{Al inicio de la actividad.}

Cuando se empleen nuevos equipos, tecnologías, preparados o sustancias o se modifique el acondicionamiento de los lugares de trabajo.

Cuando se cambien las condiciones de trabajo.

Cuando se incorpore un trabajador especialmente sensible.

Cuando se hayan detectado daños a la salud de los trabajadores.

Cuando se haya apreciado a través de los controles periódicos, incluidos los relativos a la vigilancia de la salud, que las actividades de prevención pueden ser inadecuadas o insuficientes.

Cuando así lo establezca una disposición específica, convenio colectivo o acuerdo entre empresario y representantes de los trabajadores.

\section{Peligro}

Cuando decimos que algo es peligroso se refiriere a que ese algo podría tener la capacidad o la viabilidad de hacernos daño. Por lo tanto, es peligroso todo aquello que podría hacernos daño; ya sea directamente $\mathrm{o}$ afectando los bienes. 
El peligro no siempre reside específicamente en las cosas, sino en la manera errónea, insegura o negligente en que se las maneje o se interactua con ellas. Por ejemplo, una embarcación de por sí no es peligrosa; pero sí es peligroso salir en ella cuando hay tormentas fuertes.

Mira estos ejemplos

1. Ella sabe del peligro que enfrenta si baja corriendo las escaleras.

2. Ese perro de mis vecinos es un peligro para las gallinas.

Como puedes observar, en estas oraciones la palabra "peligro" se utiliza para indicar que hay manera de que algo malo o indeseado pueda ocurrir.

Existen muchas cosas peligrosas, varios tipos de peligros; además, diferentes causas de peligro y los seres humanos no se puede evitar que estos existan, pero sí se podria reducir los riesgos de que algo logre afectarlos.

A diferencia del peligro, que tiene que ver con la "probabilidad de daño", el riesgo tiene que ver con la posibilidad de que el daño ocurra.

\section{Riesgos Laborales}

Los peligros existentes en nuestra tarea laboral o en nuestro propio entorno o lugar de trabajo, que puede provocar accidentes o cualquier tipo de siniestros que, a la vez, sean factores que puedan provocar heridas, daños físicos o psicológicos, traumatismos, etc. Sea cual sea el posible efecto, siempre es negativo para nuestra salud.

No todos los trabajos presentan los mismos factores de riesgo para el trabajador, ni estos factores pueden provocar daños de la misma magnitud. Todo depende del lugar y de la tarea que 
desempeños en el trabajo que se realiza. Por ejemplo, si soy empleado de un comercio, varios riesgos laborales podrán ser accidentes por el contacto con fuentes de energía eléctrica, posibles robos o asaltos al local comercial, accidentes provocados por escapes e inhalaciones de gas, caídas desde escaleras, heridas por rotura de vidrios, etc.

Pero muy distinto sería si lo comparo con el trabajo de, por ejemplo, mi papá, que se desempeña como empleado de un taller metalúrgico. El riesgo laboral es otro, y es más propenso a los accidentes, porque además se considera un trabajo de "fuerza": él podrá sufrir quebraduras o traumatismos por contacto con metales o elementos pesados, heridas de distinta magnitud por cortes, accidentes con máquinas eléctricas como las caladoras o las máquinas para soldar, entre otros.

Claro que muchas veces, estos accidentes pueden atenuarse o tratarse a tiempo, si, por un lado, se debe tomar precauciones cuenta propia, y, por otro lado, se debe tener un equipo de salud o de contención en nuestro trabajo.

Es muy común que las empresas o cualquier empleador, otorgue a los empleados un seguro de trabajo con cobertura médica y de pago por daños sufridos en el trabajo (incluso incluyen accidentes o daños que puedan sufrirse en el trayecto casa>trabajo y trabajo>casa).

Existen en la actualidad profesionales dedicados a la higiene y seguridad en el trabajo que, entre otras cosas, se ocupan de observar, analizar e identificar todas las acciones que pueden desencadenar un cierto accidente laboral, y que, de esta manera, se transforma en una fuente de riesgo en el trabajo para quienes desarrollan tareas que necesariamente implique realizar (de manera voluntaria o de manera involuntaria) alguna o algunas de esas acciones. 
Estos profesionales también suelen realizar reuniones o grupos focales periódicos con un grupo de trabajadores para analizar desde la opinión de ellos la calidad de las condiciones de trabajo que poseen, dentro de lo cual una de las variables a considerar es el riesgo laboral.

\section{Tipos de riesgos laborales}

Existen diferentes tipos de riegos que influyen las labores dentro de la empresa.

\section{Riesgos Físicos}

Definimos ruido a una sensación auditiva generalmente desagradable. Cuando se escucha un ruido primero se lo aprecia por el oído externo, después, la onda es recibida por el oído medio que es donde está el tímpano. Posteriormente la señal pasa por una cadena de huesecillos y la recibe el cerebro mediante unas células capilares.

Cuando el ruido es muy fuerte se activan las células capilares y hay riesgo de perder la capacidad auditiva. Se debe proteger con todas las medidas de seguridad posibles.

Las vibraciones por todo tipo de maquinaria pueden afectar a la columna vertebral, dolores abdominales y digestivos, dolores de cabeza.

El deslumbramiento, las sombras, la fatiga y el reflejo son factores producido por la iluminación. Estos elementos pueden producir un accidente por eso hay que vigilar con el tipo de lámparas y respetar los niveles adecuados de luz.

La temperatura y la humedad en el ambiente si son excesivamente altas o bajas pude producir efectos adversos en las personas. Los valores ideales en el trabajo son $21^{\circ} \mathrm{C}$ y $50 \%$ de humedad. 
Las radiaciones ionizantes son ondas electromagnéticas que alteran al estado físico sin percibirse en el ambiente. Los efectos son graves a la larga, por eso hay que limitar las ondas y tener un control médico.

\section{Riesgos Químicos}

Son producidos por procesos químicos y por el medio ambiente. Las enfermedades como las alergias, la asfixia o algún virus son producidas por la inhalación, absorción, o ingestión. Se debe proteger con mascarillas, guantes y delimitar el área de trabajo.

\section{Riesgos Biológicos}

Las enfermedades producidas por los virus, bacterias, hongos, parásitos son debidas al contacto de todo tipo de ser vivo o vegetal. Para evitarlas se recomienda tener un control de las vacunas y sobretodo protegerse con el equipo adecuado.

\section{Riesgos Ergonómicos}

La ergonomía es la ciencia que busca adaptarse de manera integral en el lugar de trabajo y al hombre. Los principales factores de riesgo ergonómicos son: las posturas inadecuadas, el levantamiento de peso, movimiento repetitivo. Puede causar daños físicos y molestos.

Este tipo de riesgo ofrece cifras relativamente altas ocupando el $60 \%$ de las enfermedades en puestos de trabajos y el $25 \%$ se deben a la manipulación de descargas.

Cuando se levanta peso la espalda tiene que estar completamente recta y las rodillas flexionadas. Si son trabajos físicos, antes de empezar se debe estirar los músculos y las articulaciones para evitar futuras lesiones. Hay que utilizar métodos seguros en todo momento. 


\section{Riesgos Psicosociales}

Algunos de estos riesgos afectan a todos en algún momento de nuestra vida laboral. Algunos de los más comunes son: estrés, fatiga, monotonía, fatiga laboral... Para prevenirlas es recomendable respetar los horarios laborales sin excederse en las horas.

Se debe tener como mínimo un descanso de 15 minutos a partir de las 6 horas. La estabilidad $\mathrm{y}$ un buen ambiente ayudaran a disminuir estos riesgos.

\section{Riesgos Mecánicos}

Este tipo de riesgos se ven reflejados a trabajos en altura, superficies inseguras, un mal uso de las herramientas, equipos defectuosos. Se debe siempre de revisar la maquinaria en la que se trabaja para evitar posibles incidentes.

\section{Riesgos Ambientales}

Estos factores son los únicos que no se puede controlar. Se manifiestan en la naturaleza la lluvia, la tempestad, las inundaciones... Se debe ser previsibles y prudentes.

Clasificación de los factores de riesgo12 Factor de riesgo:

Es un elemento, fenómeno o acción humana que puede provocar daño en la salud de los trabajadores, en los equipos o en las instalaciones. Ejemplo, sobre esfuerzo físico, ruido, monotonía.

Riesgo común: Es la posibilidad de sufrir un accidente o enfermedad durante la realización de una actividad cotidiana no laboral. 
Riesgo ocupacional: Es la posibilidad de sufrir un accidente o enfermedad en y durante la realización de una actividad laboral no necesariamente con vínculo contractual.

Riesgo profesional: Es la posibilidad de sufrir un accidente o enfermedad en y durante la realización de una actividad laboral con vínculo contractual vigente.

Acto inseguro: Son las omisiones cometidas por las personas que, al violar normas o procedimientos previamente establecidos, posibilitan que se produzcan accidentes de trabajo.

Condición peligrosa: Es la provocada por defectos en la infraestructura, en las instalaciones, en las condiciones del puesto de trabajo o en los métodos de trabajo.

Los que generan Patologías Traumáticas: Son aquéllos en que las consecuencias son de observación rápida o inmediata. Normalmente son equivalentes a los que producen Accidentes de Trabajo. Estos riesgos se acostumbra expresarlos, por la forma de accidentes que podrían provocar como mecánicos, eléctricos, incendio, ETC.

Los que generan Patologías No Traumáticas: Son aquéllos cuyas Consecuencias no son de observación rápida o inmediata. Habitualmente son equivalentes a los que producen Enfermedades Profesionales. A estos riesgos se acostumbra denominarlos, por el Factor de Riesgo, como, Por ejemplo, ruido, iluminación, contaminantes químicos, etc.

Microclima laboral: Ambientes de trabajo Se caracterizan por estresar a los trabajadores en el ambiente laboral y pueden predisponer al individuo a sufrir un accidente de trabajo con mayor probabilidad. 
Ambientales: Contaminantes del ambiente Probabilidad de ocurrencia de un fenómeno que afecta directa o indirectamente al medio ambiente al que puedan estar sometidos los seres humanos en función del trabajo.

\section{Dentro de estos están:}

FÍSICOS: Se refiere a todos aquellos factores ambientales que dependen de las propiedades físicas de los cuerpos, tales como carga física, ruido, iluminación, radiación ionizante, radiación no ionizante, temperatura elevada y vibración, que actúan sobre los tejidos y órganos del cuerpo del trabajador y que pueden producir efectos nocivos, de acuerdo con la intensidad y tiempo de exposición de los mismos.

- $\quad$ Ruido

- Temperaturas Extremas

- Iluminación

- $\quad$ Radiaciones no Ionizantes

- Vibraciones

- $\quad$ Presiones Anormales

QUÍMICOS: Son todos aquellos elementos y sustancias que, al entrar en contacto con el organismo, bien sea por inhalación, absorción o ingestión, pueden provocar intoxicación, quemaduras o lesiones sistémicas, según el nivel de concentración y el tiempo de exposición.

- $\quad$ Gases y Vapores

- Polvos Inorgánicos

- Polvos Orgánicos

- Humos

- Rocíos

- Neblinas 
BIOLÓGICOS: En este caso se encuentra un grupo de agentes orgánicos, animados o inanimados como los hongos, virus, bacterias, parásitos, pelos, plumas, polen (entre otros), presentes en determinados ambientes laborales, que pueden desencadenar enfermedades infectocontagiosas, reacciones alérgicas o intoxicaciones al ingresar al organismo.

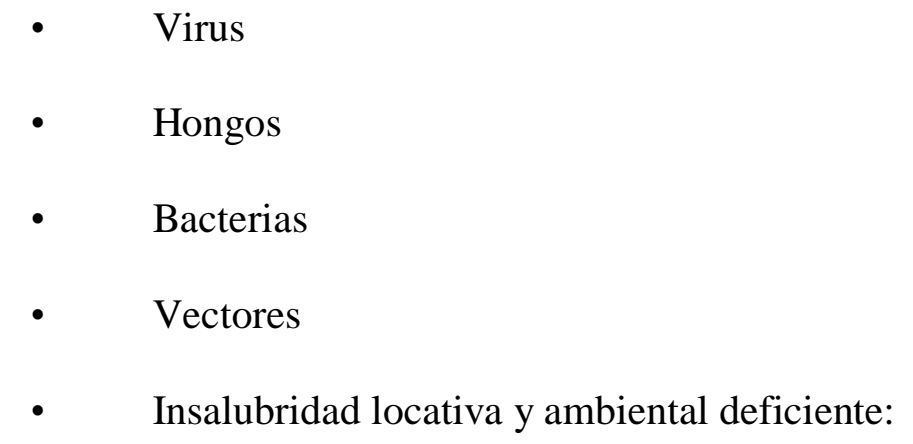

De Saneamiento: Carencia de servicios de salud que se refieren a los aspectos de promoción, prevención, curación y rehabilitación. Hábitos nocivos y carencias de hábitos higiénico-sanitarios, desconocimiento de la importancia del auto cuidado individual y familiar, estilos de vida inapropiados.

- $\quad$ Desechos y olores desagradables

- $\quad$ Acumulación de basuras

- $\quad$ Falta o mal estado de servicios sanitarios.

- $\quad$ Alcantarillado faltante o en mal estado.

- $\quad$ Sobre carga física: 
Dentro de estos están:

ERGONÓMICO: Representa los objetos, puestos de trabajo, máquinas, equipos y herramientas cuyo peso, tamaño, forma y diseño pueden provocar sobre-esfuerzo, así como posturas y movimientos inadecuados que traen como consecuencia fatiga física y lesiones osteomusculares.

- $\quad$ Posiciones forzadas

- $\quad$ Sobre esfuerzos

- Fatiga

- Ubicación inadecuada del puesto de trabajo

PSICOSOCIAL: La interacción en el ambiente de trabajo, las condiciones de organización laboral y las necesidades, hábitos, capacidades y demás aspectos personales del trabajador y el entorno social, en un momento dado pueden generar cargas que afectan la salud, el rendimiento en el trabajo y la producción laboral.

- $\quad$ Exceso de responsabilidad

- Monotonía y rutina

- $\quad$ Problemas familiares

- $\quad$ Problemas laborales

- $\quad$ Turno de trabajo extenuante y/o rotatorio.

- Psicosocial con carga psíquica: hacen parte de los factores psicosociales por carga física y también se ve afectada la psiquis del trabajador por tensiones emocionales desagradables, repetitivas y prolongadas.

- Los turnos rotativos

- Los turnos nocturnos 
- Las tareas repetitivas

- $\quad$ Alta concentración

- Inestabilidad laboral

- $\quad$ Inseguridad laboral y extra laboral

- Tareas fragmentadas

- Autoritarismo

- $\quad$ Procedimientos peligrosos

- Productores de inseguridad: Representado en el desacatamiento, desconocimiento $u$ omisión de las Normas mínimas de Seguridad establecidas en áreas de trabajo o tipos de ocupaciones específicas.

Dentro de estos están:

MECÁNICOS: Son aquellos riesgos que generan golpes y/o atrapamientos tales como choques, fricciones, caídas (al mismo nivel o de altura), cortes y proyecciones de partículas, que generan traumas, heridas, amputaciones o abrasiones en los trabajadores.

- Máquinas

- $\quad$ Equipos

- Herramientas

- Vehículos sin mantenimiento preventivo

- $\quad$ Sistemas de protección deficientes

- $\quad$ Sistemas de control obstruidos

RIESGOS LOCATIVOS: Son aquellos que se refieren a la parte física del sitio de trabajo y que al igual que todos representan un alto grado de peligrosidad. 
- Pisos

- Techos

- $\quad$ Almacenamiento inadecuado

- Muros

RIESGO HUMANOS: Son aquellas conductas inseguras o actos inseguros por falta de conocimientos, habilidad o motivación que da como resultado un accidente de trabajo o una enfermedad profesional. Fuentes de generación:

- $\quad$ Falta de inducción

- $\quad$ Entrenamiento inadecuado

- $\quad$ Supervisión inadecuada

- $\quad$ Perfil ocupacional no definido.

RIESGOS ELÉCTRICOS: Son los sistemas eléctricos de los equipos, maquinas e instalaciones locativas que al entrar en contacto con las personas pueden ocasionar daños físicos como: quemaduras, fibrilación ventricular, electrocución; de acuerdo con la intensidad y tiempo de contacto. Ejemplo: Equipos sin conexión de tierra, cables pelados, empalmes defectuosos, circuito sobrecargado, sistema energizado húmedo.

- $\quad$ Puestas a tierra

- Instalaciones en mal estado

- Instalaciones recargadas

- Sobrecargas

- Cables pelados

- $\quad$ Corto circuito 
RIESGOS NATURALES: Todos los riegos de la naturaleza

- Tormentas eléctricas

- Huracanes

- $\quad$ Terremotos

- Deslizamientos

RIESGOS FÍSICO QUÍMICOS: Son todos aquellos elementos, sustancias, fuentes de calor y los sistemas eléctricos que bajo ciertas sustancias de inflamación y combustibilidad pueden desencadenar explosiones e incendios que producen lesiones personales y materiales. Ejemplo:

- $\quad$ Cortos circuitos

- $\quad$ Sustancias y/o materiales peligrosos causantes de explosiones

- Mal almacenamiento y manipulación inadecuada de mercancía

RIESGOS TIPO PROCEDIMIENTOS PELIGROSOS: Son todos los trabajos de alto riesgo.

- $\quad$ Trabajos en alturas. Por encima de $1.50 \mathrm{cms}$

- $\quad$ Trabajos en subsuelos: por debajo de $1.50 \mathrm{cms}$

- Trabajos en espacios confinados

- Trabajos en caliente: soldadura

- $\quad$ No uso de los elementos de protección personal.

RIESGOS DE TRANSITO: Riesgo Público, todo lo que me puede suceder cuando mi labor se realiza directamente en la calle:

- Colisiones 
- Volcamiento

- Varadas

- Obstáculos

- Atracos

- $\quad$ Conflicto armado

- $\quad$ manifestaciones

\section{En la evaluación de riesgos está la clave de la reducción de peligros}

La evaluación de los riesgos acaecidos es la fase más comprometida de este abordaje, porque es la que está encargada de estimar aquellos riesgos que no pudieron ser evitados. Entonces, del análisis se deberá obtener la información necesaria para que el empresario pueda tomar de ahí en adelante medidas preventivas que eviten que una vez más otro trabajador sea objeto de algún siniestro que puede y debe evitarse.

Una vez que la evaluación se efectúa y se llega a la determinación que es necesario la toma de medidas preventivas, las mismas, deberán ser puestas de manifiesto inmediatamente en las situaciones que correspondan, con el debido aleccionamiento y advertencia a los trabajadores que alcancen.

Las dos alternativas más efectivas al respecto, serán, por un lado, eliminar de plano o reducir el riesgo mediante medidas de prevención en el origen, organizativas, de protección individual, colectiva, de formación e información a los trabajadores y, por otro lado, controlar recurrentemente las condiciones en las cuales los trabajadores desempeñan las labores, la organización que tienen, los métodos de trabajo que emplean y el estado de salud. 


\section{Prevención de riesgos laborales (PRL) y las herramientas}

Consiste en un conjunto de actividades que se realizan en la empresa con la finalidad de descubrir anticipadamente los riesgos que se producen en cualquier trabajo.

Esta anticipación permite que se puedan planificar y adoptar una serie de medidas preventivas que evitarán que se produzca un accidente laboral.

La PRL se basa en estas ideas:

- Un accidente laboral no es un suceso inevitable, algo que suceda irremediablemente, por casualidad o "porque tenía que pasar". Un accidente laboral es la manifestación de que algo no ha ido bien en el desarrollo de una tarea, de que ha habido un fallo.

- Si la tarea está bien estudiada de antemano, sabiendo cómo hay que hacerla y qué medios hay que emplear, también se podrán prever los riesgos que puedan aparecer.

Por lo tanto, cuanto mejor estudiada esté una tarea, más fácil será evitar que se produzcan "fallos" (accidentes) durante la misma.

La legislación actual se basa en el derecho de los trabajadores a un trabajo en condiciones de seguridad y salud, lo que implica un deber del empresario para conseguir esa protección.

\section{Herramientas de PRL}

Para prevenir los riesgos en el trabajo, la herramienta fundamental de los técnicos especialistas en PRL es la evaluación de riesgos.

La Evaluación de Riesgos es un estudio técnico en el que: 
Se estudian las condiciones de un puesto de trabajo: lugar, maquinaria, productos empleados,

etc.

Se identifican los peligros a los que se expone el trabajador por trabajar en esas condiciones. Puede que haya peligros que puedan ser eliminados fácilmente en esta fase; el resto, tendrán que ser evaluados.

Según el tiempo a que esté expuesto a cada uno de esos peligros y la gravedad de los daños que puedan causar, se intenta medir el riesgo a que está sometido el trabajador.

Con esto, se obtiene una lista de riesgos que puede ordenarse por mayor o menor gravedad.

Finalmente, se propondrán unas medidas preventivas para eliminar o reducir los riesgos de ese puesto de trabajo.

Tras esta primera fase en la que se detectan y miden los riesgos, la empresa deberá planificar cómo ir adoptando progresivamente las medidas que los técnicos especialistas en PRL han propuesto.

\section{Otras formas de prevención de riesgos laborales}

Al referimos a la prevención del trabajador frente al riesgo laboral parece ser que sólo hay un camino, un tipo de prevención. Sin embargo, en mi opinión existen tres en función del momento en el que el profesional prevencionista interviene. Esta cuestión no es nueva, de hecho ya en la propia ley de prevención de riesgo laborales se especifica como principios generales de la prevención aspectos tales como la evaluación de los riesgos, la adaptación persona-puesto, la sustitución de lo peligroso, anteponer la protección colectiva a la individual, dar las debidas instrucciones a los 
trabajadores, considerar las capacidades profesionales, prever las distracciones o imprudencias no temerarias......

¿Es la propia ley, muchas veces, un "cajón de sastre” al referirse al factor humano y la prevención?,

¿En necesario redactar un protocolo de actuación cuando se refiere a la prevención del factor humano en seguridad y salud laboral?.

De manera general, en psicología clínica se trabaja con tres tipos de intervención: primaria, secundaria y terciaria. Me referiré a estos tres tipos de intervención clínica adaptados a la psicología del trabajo y la seguridad y salud laboral.

La intervención primaria es aquella cuyo objetivo es eliminar o reducir la probabilidad del accidente o enfermedad. Una intervención secundaria hace referencia a aquella dirigida a fomentar los conocimientos, destrezas y habilidades. En conclusión, competencias preventivas. Finalmente, una intervención terciaria queda establecida al intentar reducir las consecuencias que pudiera producir el accidente, a través de disminución de la prevalencia o tiempo de duración, exposición a un riesgo, utilización de equipo de protección individual. ¿Es posible proteger de los riesgos al factor humano desde esta perspectiva “intervencionista”? De ser así, ¿Cuál sería el protocolo?

Se debe partir de la idea de que la conducta en general, es decir independientemente de que sea segura o de riesgo y de manera nada exhaustiva, ocurre después de que los empleados hayan percibido y evaluado el riesgo. Ésta es una cuestión nada baladí. Una intervención primaria debe basarse en la concepción que dé el empleado del riesgo al que está expuesto, partiendo de unas 
acciones correctivas y preventivas procedentes de una evaluación de riesgos cuyo objetivo último es eliminar o reducir el riesgo laboral al que está expuesto.

Si decimos que esta etapa es un inicio de intervención, la siguiente fase es trasladar "fielmente" el riesgo al conocimiento de la persona. "Fielmente", en mi opinión significa reconocer que existe el riesgo y sobre todo aceptarlo.

Si el trabajador no acepta el riesgo difícilmente tendrá una actitud favorable hacia la adquisición de conocimientos, destrezas y habilidades para evitarlo y/o gestionarlo. El estadio final se lo encuentra en un contexto en el cual no se ha podido eliminar el riesgo y por tanto se ha minimizado al máximo.

Esta cuestión de minimizar el riesgo al máximo, si se me permite la expresión, "hay que cogerla con pinzas” sobre todo porque ¿cuándo se ha minimizado un riesgo al máximo? Pero bueno, esta cuestión sería para tratarla en otro foro. Volviendo a la intervención terciaria, la utilización de los equipos de protección individual es determinante para disminuir las consecuencias de la exposición al riesgo.

\section{Las Técnicas de Prevención de Riesgos Laborales}

Son aquellas técnicas que están encaminadas a actuar directamente sobre los riesgos, antes de que se lleguen a materializar y por consiguiente puedan producir daños en la salud de los trabajadores. Son por lo tanto técnicas de tipo activo.

La Ley de PERL, establece la obligatoriedad de actuar sobre el riesgo, cuestión que cumplen a la perfección las técnicas de hombres trajeados prevención activa, ya que actúan sobre la probabilidad y la frecuencia del riesgo y en menor medida sobre las consecuencias del mismo. 
Las actuaciones preventivas en una empresa, pueden ser de tipo material o relacionadas con la formación e información de los trabajadores.

El principal problema que presentan las actuaciones preventivas de tipo material, es el enorme campo de actuación y la extraordinaria complejidad y diversidad, de las condiciones materiales que el mundo laboral ofrece hoy día, por eso a veces los límites entre unas técnicas y otras se solapan.

Estas técnicas o disciplinas preventivas son:

La Seguridad en el Trabajo: es aquella disciplina que estudia los riesgos y las condiciones materiales relacionadas con el trabajo, que podrían llegar a afectar, directa o indirectamente, a la integridad física de los trabajadores (accidente de trabajo). Se ocupa del estudio de las condiciones de seguridad de los lugares de trabajo, la adecuación de maquinaria y los equipos, la electricidad o los incendios, entre otras variables.

La Higiene Industrial o Higiene Laboral: está considerada como aquella disciplina preventiva, cuyo objetivo fundamental es identificar, evaluar, y controlar, las concentraciones de los diferentes contaminantes, ya sean de carácter físico (como el ruido), químico (como los productos químicos) o biológicos (como los virus y bacterias), presentes en los puestos de trabajo y que pueden llegar a producir determinadas alteraciones en la salud de los trabajadores y en el peor de los casos, enfermedades profesionales.

La Ergonomía: es aquella disciplina, que trata la adecuación entre las distintas capacidades de las personas y las exigencias de las capacidades demandadas por las tareas del trabajo realizado. En un principio se dirigía fundamentalmente al estudio y adecuación de las dimensiones de los 
puestos de trabajo, los esfuerzos y movimientos requeridos por las tareas, a las características físicas de las personas.

Con el tiempo se incluyeron otros aspectos como eran el medio ambiente físico, dentro del cual se incluían entre otros la iluminación, la temperatura, la humedad y los niveles de ruido. Este estudio del ambiente físico, dentro del campo de la Ergonomía, iba encaminado al estudio de las exigencias físicas y mentales de las tareas y las posibles consecuencias sobre el desarrollo de dichas tareas, con el fin de prevenir la fatiga tanto física como mental del trabajador.

La Psicosociología Laboral: es la disciplina que se encarga del estudio de aspectos tan importantes como: el tiempo de trabajo, el horario, las pausas, el ritmo de trabajo, la propia organización del trabajo, la carga mental, las relaciones laborales, etc.

La Medicina del Trabajo: es aquella disciplina (no técnica), dirigida fundamentalmente al estudio de las consecuencias derivadas de las condiciones materiales y ambientales, sobre las personas, procurando establecer, junto a las disciplinas preventivas anteriormente indicadas, unas condiciones de trabajo que no produzcan enfermedades ni daños en la salud de los trabajadores.

A la vez se ocupa del tratamiento, curación y posterior rehabilitación de las enfermedades profesionales. Con la combinación de esta metodología interdisciplinar, se puede llegar al proceso de Evaluación de los Riesgos Laborales, que se constituye en la herramienta o medio, de la que va a disponer el empresario, para identificar los riesgos y posteriormente planificar todas las actividades preventivas que sean necesarias, en el seno de la empresa. 


\section{Recomendaciones para prevenir los riesgos laborales}

Para una correcta prevención de los riesgos laborales, se requiere, primero evaluar los posibles riesgos e incumplimientos que puedan estar ocurriendo en los diferentes puestos de trabajo de una organización y luego se debe eliminar los riesgos que sean evitables y minimizar los no evitables para tener un ambiente de trabajo adecuado y seguro.

En este sentido, se describen, a continuación, recomendaciones para evitar los riesgos laborales:

Guardar los productos químicos inflamables forma separado, no deben trasvasarse, los recipientes deben estar herméticamente cerrados y en locales bien ventilados. A la hora de manipular estos productos, deben hacerse con equipos de protección adecuados.

Verificar que los trabajadores cuenten con una silla adecuada y otras herramientas ergonómicas. Es necesario, también, informarles de la necesidad que cambien de postura frecuentemente, alternado tareas y establecer pausas para descansar

Supervisar que los trabajadores, al manipular cargas, utilicen los equipos adecuados. Debe hacerse hincapié que las cajas en el suelo deben levantarse con las rodillas y la cadera flexionadas, con los pies firmemente apoyados en el suelo y ligeramente separados.

Evitar riesgos que son generales a cualquier tipo de actividad: resbalones, caída en altura o quemaduras. Para ello, los suelos tienen que estar despejados de obstáculos, no ser resbaladizos y todos los espacios deben estar adecuadamente iluminados. 
Evitar que los trabajadores manipulen aparatos eléctricos en mal estado ni en contacto con el agua y se debe contar con un extintor que el trabajador debe saber usar.

\section{Conclusiones.}

Los riesgos laborales se evalúan en una empresa al inicio de la actividad, cuando se empleen nuevos equipos, tecnologías preparadas o sustancias o el acondicionamiento del lugar de trabajo, cambios en las condiciones de trabajo, cuando se incorpore unos colaborados especialmente sensibles, se detecte daños a la salud de los trabajadores.

Los tipos de riesgos laborales son físicos, químicos, biológicos, ergonómicos, psicosociales, mecánicos, ambientales. Los factores de riesgo se clasifican en común, ocupacional, profesional, acto inseguro, condición peligros, los que genera patologías traumáticas y no traumáticas, microclima laboral, ambientales, éstos últimos se subdividen en físicos, insalubridad locativa y ambiental deficiente, sobre carga física, psicosocial con carga psíquica, productores de inseguridad cuando se realiza un trabajo.

La evaluación de riesgos tiene dos alternativas, por un lado eliminar de plano o reducir el riesgo mediante medidas de prevención en el origen en los trabajadores, y por otro lado, controlar recurrentemente las condiciones en las cuales los trabajadores desempeñan las labores, la organización que tienen, lo métodos de trabajo que emplean y el estado de salud.

La prevención de riesgos laborales tiene la finalidad de descubrir anticipadamente los riesgos que se producen en el ambiente de trabajo, está anticipación permite que puedan planificar y adoptar medidas preventivas que eviten que se produzca un accidente laboral y el trabajador pueda realizar 
sus actividades en un lugar con condiciones de seguridad y salud, por lo que la empresa debe conseguir esta protección.

Las recomendaciones para prevenir los riesgos laborales se requiere primero evaluar los posibles riesgos e incumplimientos que puedan estar en el puesto de trabajo del colaborador de la empresa, posteriormente se debe eliminar los riesgos posibles y cumplir con todas las medidas impuestas por la organización verificando que los trabajadores se encuentre en un ambiente de seguridad y salud.

\section{Bibliografía.}

Administración. Definición de administración. Qué es, Significado y Concepto. Disponible en: http://definicion.de/administracion/\#ixzz4G6CzPNeF

Clasificación de los factores de riesgo. Clasificación y subclasificación de factores de riesgo. Agroietal3. Disponible en: https://agroietal3.wordpress.com/clasificacion-y-subclasificacion-de-factores-deriesgo/

Definición de Riesgo laboral, Definición ABC. Disponible en: http://www.definicionabc.com/salud/riesgolaboral.php

Empleado. Definición de empleado. UniversoJus.com. Disponible en: http://universojus.com/definicion/empleado

Empresa. Definición de Empresa. Definición ABC. Disponible en: http://www.definicionabc.com/economia/empresa.php

Empresa. Definición de Empresa. Disponible en: https://emprendimientocemm.wikispaces.com/file/view/Definicion+de+Empresas.pdf

Evaluar los riesgos. Evaluar los riesgos. Guía Laboral - La prevención de riesgos laborales. Disponible en: http://www.empleo.gob.es/es/guia/texto/guia_10/contenidos/guia_10_22_1.htm

Factor de riesgo. Riesgos laborales. Disponible en: http://www.gestion-sanitaria.com/3-riesgos- laboralesconceptos-basicos.html

Herrán Gamarra, Fco. Javier. (2014, 5 de Octubre). "Tres tipos de prevención del riesgo laboral". www.prevencionintegral.com. Disponible en: http://www.prevencionintegral.com/comunidad/blog/psicoprevencioncom

Labor. Concepto de labor. Definición en DeConceptos.com. Disponible en: http://deconceptos.com/ciencias-sociales/labor\#ixzz4Nve37fr6 
Navarro, F. (2013), Las Técnicas de Prevención de Riesgos Laborales, INESEM, Disponible en: http://revistadigital.inesem.es/gestion-integrada/las-tecnicas-de-prevencion-de-riesgos- laborales/

Peligro. Definiciones de peligro y riesgo en palabras sencillas. Chile prevención. Disponible en: http://www.chileprevencion.cl/definiciones-de-peligro-y-riesgo.html

Prevención de riesgos laborales(PRL). Trabajadores prevención de riesgos laborales. OBALAN. Disponible en: http://www.osalan.euskadi.eus/s94osa0050/es/contenidos/informacion/trabajadores_prevencion/es_prevenc/trabajadores_prevenc ion.html

Recomendaciones para prevenir riesgos laborales. Cómo previnir los riesgos derivados del trabajo. RRHHwewb.com. Disponible en: http://www.rrhhweb.com/Como_prevenir_los_riesgos_profesionales.html

Riesgos Laborales. Definición de riesgo laboral. Definición. Disponible en: http://definicion.mx/riesgolaboral/

Riesgos. Que es riesgo. Unisdr.org. Disponible en: https://www.unisdr.org/2004/campaign/bookletspa/page9-spa.pdf

Tipos de riesgos laborales. 7 tipos de riesgos laborales. El portal de la coordinación empresarial.

Disponible en: http://www.coordinacionempresarial.com/tipos-de-riesgos-laborales/ 